\title{
As tres Cidras do Amor, ou $O$ Cavalleiro Andante (1793)
}

\author{
Pedro Álvarez-Cifuentes*
}

\begin{abstract}
Resumen
Pese a la tardía publicación de la versión en lengua portuguesa de Don Quijote de la Mancha (1794), el conocimiento de la novela cervantina en Portugal puede rastrearse a lo largo del siglo XVIII y se hace especialmente patente en el dominio teatral. Tal es el caso de la «piquena pessa» anónima titulada As tres Cidras do Amor, ou O Cavalleiro Andante (Lisboa, Off. de Francisco Borges de Sousa, 1793), que pone en escena una singular recreación del hidalgo castellano y del efecto alucinador de la lectura de los libros de caballerías. Se propone una presentación de la farsa As tres Cidras do Amor y un análisis de la parodia que realiza sobre el universo ficcional de la caballería andante.
\end{abstract}

Palabras clave: Don Quijote; Cervantes; literatura portuguesa; teatro; farsa.

Title: As tres Cidras do Amor, ou O Cavalleiro Andante (1793)

\begin{abstract}
Even though the Portuguese version of Don Quijote de la Mancha was published as late as 1794 , there is evidence that attests to the knowledge of the novel in Portugal during the entire eighteenth century, especially in the theatrical domain. An example is the anonymous «piquena pessa» entitled As tres Cidras do Amor, ou O Cavalleiro Andante (Lisbon, Off. de Francisco Borges de Sousa, 1793), which stages a singular recreation of the Spanish hidalgo and the hallucinatory effects of the reading of books of chivalry. I undertake a descriptive analysis of the farce As tres Cidras do Amor, focusing on its parody of the fictional universe of knight-errants.
\end{abstract}

Keywords: Don Quijote; Cervantes; Portuguese Literature; Theatre; Farce.

* Universidad de Oviedo. alvarezcpedro@uniovi.es / ORCID iD: https://orcid.org/0000-00030317-691X. 
Cómo citar este artículo / Citation

Álvarez-Cifuentes, Pedro. 2020. «As tres Cidras do Amor, ou O Cavalleiro Andante (1793)». Anales Cervantinos 52: 353-363, https://doi.org/10.3989/anacervantinos.2020.014.

\section{Don Quijote cabalga en Portugal}

La influencia del Quijote sobre la literatura en lengua portuguesa constituye un tema de notable interés en el panorama de los estudios ibéricos y la literatura comparada hispano-portuguesa ${ }^{1}$. A los trabajos pioneros de Fidelino de Figueiredo (1920 y 1921), José Ares Montes (1952 y 1953) y Edward Glaser (1955 y 1956) cabe añadir, en las últimas décadas, las investigaciones de especialistas como Maria Fernanda de Abreu (1997 y 2006), Maria Idalina Resines Rodrigues (2006), Aurelio Vargas Díaz-Toledo (2012a, 2015 y 2018) o Alexia Dotras Bravo (2016).

Como es bien sabido, pese a la tardía publicación ${ }^{2}$ de la primera versión en lengua portuguesa de Don Quijote de la Mancha en 1794, el conocimiento y la popularidad de la novela cervantina en Portugal pueden rastrearse a lo largo de los siglos XVII y XVIII y se hacen especialmente patentes en el dominio teatral, proteico y más receptivo a todo tipo de modas e influencias ${ }^{3}$. Uno de los primeros ejemplos registrados es el Entremez de Don Quijote, publicado en 1709 dentro de la compilación Musa jocoza de varios entremezes portuguezes \& castelhanos por un autor escondido bajo el pseudónimo «Nuno Nisceno Sutil». Este Entremez de Don Quijote, editado por Miguel Herrero (1948) y, más recientemente, por Abraham Madroñal (2008), fue escrito en lengua castellana por un autor de aparente origen portugués y daría inicio «en el teatro del país vecino [a] la moda de las imitaciones del Quijote» (Madroñal 2008, 313).

Mucho más popular resulta la Vida do Grande D. Quixote de la Mancha e do Gordo Sancho Pança de António José da Silva, llamado «O Judeu» (1705-1739), una ópera de marionetas (o «bonifrates») tal vez inspirada por el entremés de Nisceno Sutil y estrenada en el Teatro do Bairro Alto de Lisboa en 1733. En su escena más famosa (y disparatada) don Quijote llega a la conclusión de que los maléficos encantadores han ocultado la belleza sin par de Dulcinea del Toboso bajo la figura del gordo Sancho Panza ${ }^{4}$. En el terreno

1. Sobre la relación de Miguel de Cervantes con Portugal, véanse los estudios editados por Vargas Díaz-Toledo y Lucía Megías (2018).

2. Sobre la primera traducción del Quijote al portugués, cfr. Abreu (1997, 75-77) y Cobelo (2010).

3. Jurado Santos (2005) elabora una bibliografía de piezas teatrales del siglo XVII derivadas de la obra cervantina, en la que la presencia portuguesa resulta muy escasa. Siguiendo a Ares Montes, Glaser $(1955,201)$ relacionaba el limitado conocimiento de la primera influencia cervantina en Portugal con «the lack of adequate bibliographical guides and the extreme rarity of many Portuguese works published in the seventeenth century».

4. Para un análisis comparado de Don Quijote de la Mancha y la Vida do grande D. Quixote, pueden consultarse, por ejemplo, Friedman (1997), Costigan (2009) y Vieira (2019). 
musical, cabría mencionar los «intermezzi a sei voci» supuestamente atribuidos a Domenico Scarlatti bajo el título Il D. Chisciotte della Mancia e interpretados durante los festejos de Carnaval organizados por la reina D. ${ }^{a}$ Maria Ana de Austria en el Palacio da Ribeira de Lisboa en 1728, que volvieron a representarse en varias ocasiones hasta 1734 (Brito 1989, 8-10; Stiffoni 1998).

Otro texto menos conocido es el Entremez Intitulado $O$ Grande Governador da Ilha dos Lagartos, publicado de manera anónima en $1784^{5}$, que constituye en realidad una fiel adaptación -si no un plagio- de las escenas IV y V de la Parte II de la Vida do Grande D. Quixote de la Mancha e do Gordo Sancho Pança, lo que vendría a confirmar el notable éxito de la obra dramática de António José da Silva casi cincuenta años después de su muerte en el cadalso de la Inquisición. Un rasgo interesante de las versiones portuguesas, destacado por la crítica (Rodrigues 2006, 177), sería la identificación de la ínsula Barataria cervantina con la «Ilha dos Lagartos», nombre legendario para la isla de São Tomé que ya aparece en la Consolaçam as Tribulaçoens de Israel del sefardí Samuel Usque (1553), lo que permite adivinar un cierto trasfondo criptojudaico de los textos ${ }^{6}$. Para Palma-Ferreira $(1981,111)$, «sob a comicidade do célebre episódio do governador dos Lagartos, [...] se esconde uma sátira rotunda e um pessimismo audaz». Las islas de los Lagartos ya son mencionadas por la condesa Trifaldi como remoto lugar de destierro en el capítulo 38 de la segunda parte del Quijote ${ }^{7}$. Ares Montes $(1953,352)$ refiere también una farsa perdida del setubalense Francisco José Monteiro Nayo, titulada D. Quixote renacido, que es citada por Diogo Barbosa Machado en su Bibliotheca Lusitana (1747, II, 167).

Aparte de las alusiones a don Quijote y Sancho que aparecen en el teatro del árcade Manuel de Figueiredo y de la sátira Quixotada de Nicolau Tolentino de Almeida -que hace mofa de la caída en desgracia del marqués de Pombal tras la muerte del rey D. José I en 1777 (Abreu 1997, 72-73)-, vamos a centrarnos en esta ocasión en el análisis de la Piquena Pessa intitulada As tres Cidras do Amor, ou $O$ Cavalleiro Andante, que fue publicada como folheto de cordel anónimo en la oficina lisboeta de Francisco Borges de Sousa en 1793, «com licença da Real Meza da Commissão Geral sobre o Exame, e Censura dos Livros» ${ }^{8}$. Hemos localizado dos ejemplares del texto en la Biblioteca Nacional de Portugal bajo las signaturas L. 3004//26 V. y L. 3338//8 A., conservados en dos compilaciones facticias tituladas, respectivamente,

5. Ares Montes $(1953,350)$ menciona una edición impresa en la «Officina de Francisco Sabino dos Santos» en 1774. La edición conservada en la Biblioteca Nacional de Portugal apareció en 1784 en la «Officina de Francisco Borges de Sousa», la misma que publicaría una década después As tres Cidras do Amor, ou O Cavalleiro Andante.

6. Guerrini (2001) aporta nuevos datos sobre la vida y obra de Samuel Usque.

7. Dice la condesa Trifaldi, o dueña Dolorida: «Desde entonces, viendo el mal en que caí por estos y otros semejantes versos, he considerado que de las buenas y concertadas repúblicas se habían de desterrar los poetas, como aconsejaba Platón [...]. Y, así, digo, señores míos, que tales trovadores con justo título los debían desterrar a las islas de los Lagartos» (Cervantes 2011, 843-844).

8. Tan solo Rodrigues $(2006,178)$ realiza un análisis muy somero de As tres Cidras do Amor, ou O Cavalleiro Andante. 
Collecção de Entremezes I (ca. 1750-1794) y Novos e divertidos entremezes (1783-1794), que incluyen obras de autores como José Daniel Rodrigues da Costa y Pedro António Pereira, entre otros. Solo el ejemplar L. 3338//8 A. está completo (16 páginas), ya que el ejemplar L. 3004//26 V. presenta un salto de la página 13 a la 16. En la Biblioteca de Arte de la Fundação Calouste Gulbenkian de Lisboa se conserva otra copia incompleta de As tres Cidras do Amor (con solo 8 páginas), bajo la signatura TC 152. Constan también otros cuatro ejemplares: en la Biblioteca Nacional de España [R/12717(9)], en la «Col-lecció Cervantina» de la Biblioteca de Catalunya [ms. 1297], en la Bibliothèque nationale de France [8-YTH-72266] y en la Bancroft Library de la Universidad de California en Berkeley [p PQ9261.A1 P5 1793].

Así, As tres Cidras do Amor, ou O Cavalleiro Andante puede aparecer catalogada como entremez, si bien hemos de tener en cuenta que el término no tiene exactamente el mismo significado en español y en portugués9. José Oliveira Barata $(1995,292-293)$ define el entremez portugués como «um género dramático curto em que intervêm personagens de carácter popular e de tom preferentemente cómico, [...] capaz de competir com a comédia, o auto e toda a multiforme variedade da literatura de cordel [...], com uma produtividade que atinge um ponto alto no último terço do séc. XVIII», con el tremendo éxito de autores como José Daniel Rodrigues da Costa, Leonardo José Pimenta y Nicolau Luís da Silva ${ }^{10}$. Como apuntábamos, As tres Cidras do Amor circuló anónima bajo la denominación «piquena pessa», una adaptación del género francés «petite pièce», que Ignacio de Luzán describía en sus Memorias literarias de París $(1751,88)$ como «una Comedia pequeña, reducida á un Acto, á dos, ó á tres. Tiene su fábula, ó assunto perfecto, con principio, medio y fin, aunque sin episodios, ó pocos, y muy breves». La pieza que vamos a analizar se ajusta, como veremos, a la definición propuesta por Luzán ${ }^{11}$.

\section{LAS TRES CIDRAS DEL AMOR}

El título As três cidras do amor hace referencia a un conocido cuento popular de origen mediterráneo ${ }^{12}$, que ya figura en la última jornada del Cunto de li cunti (o Pentamerone) de Giambattista Basile (1634-1636) y que fue llevado al teatro por Carlo Gozzi en L'amore delle tre melarance (1761). Esta fiaba scenica del conde Gozzi, a su vez, sería adaptada por Serguéi Prokófiev

9. Sobre entremeses de inspiración quijotesca, véase Escudero Baztán (2016). Castaño (2017) analiza las diferencias entre el entremés español, el entremez portugués y el sainete.

10. Acerca de la literatura de cordel en Portugal, $c f r$. Barata (1991) y Nogueira (2012) y, más específicamente sobre el teatro popular, Sampaio (1920) y Camões (2016). Abreu (1997, 74-75) refiere algunas otras alusiones a la novela de Cervantes en folhetos de cordel como el titulado Monstruoso parto da famosa giganta de Coimbra, chamada Goliacia Trumba (1741).

11. Santos (2013) investiga la recepción de la comedia francesa en Portugal.

12. Kawan (2004) ofrece un análisis mitogenético del cuento popular «El amor de las tres naranjas» y sus múltiples variantes. 
en la ópera El amor de las tres naranjas de 1921. La versión portuguesa del cuento -que narra la historia de un melancólico príncipe que recibe el regalo de tres naranjas (o limones, o granadas, o nueces, según la fuente), que en realidad son tres doncellas hechizadas que imploran agua fresca para ser liberadas de su encantamiento ${ }^{13}$ - fue recogida por Teófilo Braga (1883) y Consiglieri Pedroso (1910), y sirvió de inspiración a una pieza de teatro infantil de Yvette K. Centeno (1991) ${ }^{14}$.

Sin embargo, a pesar del título, el argumento de esta «piquena pessa» de finales del siglo XVIII tiene poco que ver con el cuento tradicional y más con la inmortal novela de Cervantes. As tres Cidras do Amor, dividida en tres breves escenas de ágil prosa con algunos pareados intercalados, presenta al hidalgo D. Camelião, un viejo enloquecido - como Alonso Quijano- por la lectura obsesiva de libros de caballerías como el Florisel de Niquea, el Belianís de Grecia y la Crónica do Imperador Clarimundo: «Bellos Livros [que] merecem encardenados em veludo, e chapejados de ouro, e diamantes» $(1)^{15}$. $\mathrm{Su}$ favorito es, tal vez, la Historia de Carlos Magno ${ }^{16}$, «alivio de çapateiros, escola de Lacaios, assombro de Marujos, e admiração de todo genero de galegos» (1). Su esposa, la temperamental D. ${ }^{a}$ Algazarra, está harta de las extravagancias de su marido y, como el ama y la sobrina de don Quijote, está dispuesta a quemar su biblioteca y «fazer-lhe os Livros em pedaços» (1). El mitómano D. Camelião lamenta la incomprensión y la «furia indiabrada» de su mujer, que en su opinión roza la blasfemia al atreverse a ultrajar en su presencia sus amados libros, «estas estimaveis reliquias da precioza, e antequissima antiguidade, em que tanto florecerão os mais sublimes alumnos da famozissima Cavallaria andantesca» (2).

Las dos hijas del matrimonio, Dulcinea y Clarinda, «mulheres feitas, e direitas» (2) según su madre, están enamoradas de Farfante, un aprendiz de sastre, y de Palermo, un ayudante de pastelero, pero D. Camelião pretende encontrar-

13. En la excelente traducción de César Palma del cuento de Basile, una vieja hechicera recomienda al príncipe Ciommetiello: «En cuanto estés en las proximidades de tu reino, en la primera fuente que encuentres corta una toronja, de la que saldrá un hada que te dirá ¡dame de beber! Y tú has de acudir rápido con el agua, porque si no se disolverá como argento vivo. Y, si tampoco sabes ser listo con la segunda hada, abre bien los ojos y sé solícito con la tercera, para que no se te escape; dale en seguida bien de beber, que así tendrás una mujer como la quiere tu corazón» (Basile 2006, 452).

14. En su tesis doctoral As fontes do romanceiro de Almeida Garrett: uma proposta de edição crítica (Universidade Nova de Lisboa, 2011), Sandra Boto identifica una recreación de As três cidras do amor entre los romances inéditos de Almeida Garrett. Para una versión incompleta en prosa, subtitulada «conto afonsinho», véase Garrett (2015, 137-151).

15. Los títulos son citados erróneamente como «D. Floricel de Niquecia» y «D. Bliani[s] de Gaula», lo que revelaría un conocimiento defectuoso de los textos originales por parte del autor anónimo (o del editor). Sobre los libros de caballerías en Portugal, cfr. Vargas Díaz-Toledo (2012b).

16. Podría tratarse de una versión portuguesa de la Hystoria del emperador Carlo Magno y de los doze pares de Francia atribuida a Nicolás de Piamonte, o de alguna de sus continuaciones, como la Historia do Emperador Carlos Magno, e dos doze Pares de França de Jerónimo Moreira de Carvalho (1728, con varias reimpresiones) o la Historia nova do Emperador Carlos Magno, e dos doze pares de França de José Alberto Rodrigues (1742). 
les un partido mejor. El viejo confunde la realidad con la historia inventada del rey Alcureceu de Trapisonda ${ }^{17}$, que «por se livrar de boccas do Mundo» encerró a sus hijas «em tres Castellos [encantados no Vale das Cidras], guardadas huma por hum Dragão, outra por hum Gigante, e outra por huma Bixa de sete cabeças» (2), de manera que «aquelles [Principes aventureiros] que as desencantassem serião seus maridos, [os quais] derão ás Princezas o titulo de tres Cidras do Amor» (3). Con un cierto prurito de clase, D. Camelião considera que Dulcinea y Clarinda, como «filhas de hum Andante Cavalleiro, devem ser como as tres Cidras do Amor incantadas, e espozadas com aquelles aventureiros, que as desencantarem» (4-5). Puesto que solo tiene dos hijas, el papel de la tercera princesa lo cumplirá la criada, la chismosa Correqueira.

D. ${ }^{a}$ Algazarra, mucho más realista que su marido, desprecia las historias de viejas o «contos da carouxinha» y prefiere casar a sus hijas con dos aprendices honestos antes que con un par de donjuanes de noble pero empobrecido linaje, «peraltas andantes, que com duas cadeias sem relojo penduradas nos calsoens, e hum annel de vidro no dedo, affectando de Morgados ricos, andão explorando janellas, desencantando, e desenquietando a mais sezuda, e recolhida moça» (3).

Sin hacerle caso, D. Camelião ordena encerrar a Dulcinea y Clarinda en sus aposentos, donde «ficarão encantadas, e quem as quizer, que as desencante, para o que fiz lançar por toda a Cidade voz, e fama» (7). Asimismo, manda traer una serie de monigotes, monstruos y alimañas hechos de pasta de papel, «[dos] que servirão nos touros o anno passado» (8), que funcionen como guardianes del encantamiento, y recomienda a su esposa: «Vamos pois a dispor quanto for justo, / $\mathrm{E}$ das feras meu bem não tenha susto» (8).

En la segunda escena de la farsa, la criada Correqueira solicita ayuda a su novio Melquetrefe, el sirviente del sastre Farfante, que compara el escaso patrimonio de su amo con el de Sancho Panza cuando fue gobernante de la isla de los Lagartos (una referencia a la «ópera jocosa» de António José da Silva ${ }^{18}$ ). El astuto Melquetrefe, heredero de los pícaros criados del teatro del Siglo de Oro, promete tejer un enredo tal «que se o velho está meio loco, o fique de todo quando vir as filhas por suas proprias mãos espozadas com que elle desprezava» (9). A continuación, Melquetrefe explica a Farfante y a Palermo que D. Camelião ha ordenado que sus hijas «a imitação daquellas Princezas só espozem tres Cavalleiros Andantes, que em campal batalha as desencantem á ponta de lança» (10) y les pide dinero «para alugar no Theatro tres vestidos de armas brancas, e algumas mascaras para huma chusma de Pretos trombeteiros» (11). Así, disfrazados de caballeros, podrán enfrentarse a la «pessima lição de Carlos Magno, e D. Quixote de Lamancha» (10), que ha sorbido los sesos al viejo hidalgo.

17. La historia del rey Alcureceu de Trapisonda y sus tres hijas, no registrada anteriormente, parece ser una invención del autor de As tres Cidras do Amor.

18. El nombre de un paladín imaginario que menciona D. Camelião, Agilvas Salsifraz, también podría estar inspirado en D. Gilvaz, uno de los protagonistas de las Guerras do Alecrim e Mangerona de António José da Silva (1744). 
En la tercera y última escena, D. Camelião organiza el desfile de los fantoches de papel que han de custodiar la prisión de sus hijas: «Vossa altura Senhor Gigante guardará aquelle Castello de Dulcineia, vossa enormidade Senhor Dragão o de Clarinda, e a serpentissima pessoa o Castello de Correqueira» (12-13). La señora Algazarra se queja de la burda función orquestada por su marido, ya que cuando los pretendientes descubran que los monstruos están hechos de papel, «zombarão de vós, e dos vossos encantos» (12). El hidalgo, a medio camino entre el delirio y la sensatez, se defiende con el siguiente argumento: «Que vos parece a vós, que erão os Gigantes, e Dragões, e Hidras da antiguidade? Tudo erão sombras, e quimeras para se esperimentarem os coraçoens intrepidos, e logo que erão vencidas tudo se accommodava com o cazamento, que he o buziles destas farofias» (12).

Entran entonces en escena Melquetrefe, Farfante y Palermo disfrazados de caballeros, «vestidos de armas brancas, vizeiras calladas, e lanças no recto» (14), que han alquilado en un teatro cercano. Melquetrefe preside la tropa, acompañado de un séquito de trompeteros africanos y mostrándose ante D. Camelião como un intrépido espadachín: «Eu fui quem acompanhou os doze Pares na contenda da Barca de Pontavel, e ao primeiro golpe da minha Maria Francisca cortei o collo ao Cavallo Marinho, de cujo eco estremecendo a terra se devidio o orbe em quatro partes como hoje se nota» (13).

Dirigidos por Melquetrefe, los galanes simulan romper el encantamiento, destrozando los monigotes de papel con sus espadas alquiladas, y liberan a Dulcinea y a Clarinda, que los reciben alborozadas y caen rendidas en sus brazos. El sastre Farfante se anuncia ante un maravillado D. Camelião como «Marquez de Val de Tezoura» y el pastelero Palermo como «Conde de Val de Fornos [...], Senhor de Vila Torta, Vila Empada, Vilar de Pasteis» (15). Por su parte, el pícaro se presenta a sí mismo como «Principe dos Melquetrefes, Duque dos Farfantes, Marques dos Paralvilhos, e logrador mor de todos os papelloens, com particular alçada sobre os velhos loucos infactuados em Cavallarias andantes» (15).

Una vez enfrentado a la realidad, D. Camelião no tiene más remedio que aceptar los matrimonios desiguales de sus hijas, sin abandonar del todo su visión romancesca de la vida: «Eu me dou por convencido, e pois o que está feito não tem remedio, o Ceo os fará santos» (15). El criado Melquetrefe cierra la pieza reuniéndose con su querida Correqueira, que acepta convertirse en su esposa, y expresando su deseo de «que me faça bom proveito a mim, e aos dous espozados a nova aventura das tres Cidras do Amor» (16).

\section{LA PARODIA DE LA CABALLERÍA}

Pese a su aparente sencillez compositiva, la pieza As tres Cidras do Amor, ou $O$ Cavalleiro Andante está llena de guiños -más o menos obvios- a la tradición caballeresca y cervantina, lo que multiplica su interés y su valor 
literario y permite rastrear la presencia del Quijote en la literatura portuguesa del siglo XVIII, con una dimensión eminentemente cómica. El protagonista, D. Camelião, nos remite a Camilote, el caballero ridículo de la Tragicomedia de Don Duardos de Gil Vicente y también al emperador Primaleón, ancestro de los Palmerines y héroe de las lides novelescas ${ }^{19}$. Como resulta evidente, Dulcinea era un nombre bien conocido por el público portugués de la época, muy familiarizado con los personajes del Quijote, y Clarinda es la princesa que protagoniza la Crónica do Imperador Clarimundo, el primer libro de caballerías en lengua portuguesa, publicado por el historiador João de Barros en 1522 y reeditado varias veces a lo largo del siglo XVIII. Los otros personajes también tienen nombres parlantes, que contribuyen al efecto general de comicidad: D. ${ }^{a}$ Algazarra (= Doña Gritona / Algazara), Correqueira (= Correhuela / Correveidile), Farfante (= Farsante / Farfantón), Palermo (= Palurdo) y Me[1]quetrefe.

No sabemos si la pieza llegó a ser representada (antes o después de su publicación en folleto de cordel), pero el tono general de As tres Cidras do Amor es de commedia dell'arte ${ }^{20} \mathrm{o}$ de farsa costumbrista. Frente al idealismo estético del Neoclasicismo, presenta un ambiente realista y netamente burgués, con numerosos malentendidos y juegos de palabras, falsos latinismos, discusiones conyugales y una cierta atención a la lucha de clases (entre criados y señores) que también aparece en la obra coetánea de José Daniel Rodrigues da Costa y de Nicolau Luís da Silva ${ }^{21}$. Maria Idalina Rodrigues (2006, 178) apunta que nos hallaríamos ante un caso de trama de inspiración quijotesca ajustada «ao paladar da gente leitora e espectadora de finais do século XVIII». Como hemos visto, hay referencias explícitas a la novela de Cervantes y a la parodia que realiza sobre los equívocos y patrañas de los libros de caballerías, que, como se queja D. ${ }^{a}$ Algazarra a sus hijas, llegan a empañar la visión de la realidad y las relaciones familiares, hasta el punto de que el viejo hidalgo prefiera que sus hijas sean princesas encantadas y no esposas de hombres decentes: «A lição dos malditos Livros de Cavalaria, tem tornado doido vosso Pai, e arruinado todas as vossas esperanças; novamente embelezado na Historia das tres Cidras do Amor, vos quer Princezas incantadas, e não Espozas de homens officiaes» (5).

Convertido como don Quijote en objeto de las burlas del resto de personajes, D. Camelião tiende a confundir la verdad con la ficción novelesca, en

19. Como le ocurre a don Quijote con Aldonza Lorenzo, en la pieza de Gil Vicente el «cavaleiro salvagem» Camilote está enamorado de la feísima Maimonda, a la que, en su delirio, considera única merecedora de la guirnalda de rosas que identifica a la dama más hermosa del mundo (LópezRíos Moreno 1997). La aventura de Camilote es una trama secundaria del libro de caballerías Primaleón (1512). Sobre la relación del personaje de Camilote con don Quijote, véase Alonso (1968).

20. Sobre la commedia dell'arte, pueden consultarse las monografías de Nicoll (1963) y Molinari (1985). Miranda (1990) rastrea la presencia del teatro italiano en el Portugal setecentista.

21. Acerca del teatro portugués del siglo XVIII, cfr. Braga (1871), Sampaio (1920), Palma-Ferreira (1981, 109-112) y Camões (2016). Por ejemplo, en la comedia $A$ virtude sempre triunfa, ou Perseo e Andromeda (1790), atribuida a Nicolau Luís, el gracioso Boliçoso hace referencia a las aventuras de don Quijote y Sancho Panza (Glaser 1955, 207). 
contraste con los prosaicos comentarios de su esposa y de la sirvienta Correqueira. Por su parte, los dos galanes burgueses (Farfante y Palermo), armados con el atrezzo de un teatro, suponen una visión grotesca de Amadís, Florisel, Belianís y los otros paladines caballerescos. Invirtiendo los estereotipos, el pícaro Melquetrefe se convierte en el verdadero héroe de la historia al tramar el enredo que librará a las hijas del loco D. Camelião de la prisión paterna. Al final, la realidad acaba superando a la ficción y consigue derrotar el simulacro de los dragones, los gigantes y las hidras de papel.

\section{BIBLIOGRAFÍA CITADA}

Abreu, Maria Fernanda de. 1997. Cervantes no romantismo português. Cavaleiros andantes, manuscritos encontrados e gargalhadas moralissimas. Lisboa: Estampa.

Abreu, Maria Fernanda de. 2006. «O Quixote na voz dos escritores portugueses». En Dom Quixote. A letra e os caminhos, org. Maria Augusta da Costa Vieira, 297-316. São Paulo: Universidade de São Paulo.

Alonso, Dámaso. 1968. «El hidalgo 'Camilote' y el hidalgo 'don Quijote'». En Del siglo de Oro a este siglo de siglas, 20-28. Madrid: Gredos.

Ares Montes, José. 1952. «Cervantes en la literatura portuguesa del siglo XVII». Anales Cervantinos II: 193-230.

Ares Montes, José. 1953. «Don Quijote en el teatro portugués del siglo XVIII». Anales Cervantinos III: 349-352.

Barata, José Oliveira. 1991. História do teatro português. Lisboa: Universidade Aberta.

Barata, José Oliveira. 1995. «Entremez». En Biblos: Enciclopédia Verbo das Literaturas de Lingua Portuguesa II, dir. José Augusto Cardoso Bernardes, 292-296. Lisboa: Verbo.

Basile, Giambattista. 2006. Pentamerón. El cuento de los cuentos, trad. César Palma. Madrid: Siruela.

Braga, Teófilo. 1871. Historia do Theatro Portuguez. A Baixa Comedia e a Opera. Seculo XVIII. Oporto: Imprensa Portugueza.

Braga, Teófilo. 1883. Contos Tradicionaes do Povo Portuguez: com um Estudo sobre a Novellistica Geral e Notas Comparativas. Oporto: Livraria Universal.

Brito, Manuel Carlos de. 1989. Opera in Portugal in the Eighteenth Century. Cambridge: Cambridge University Press.

Camões, José. 2016. «Labirintos inconstantes entre palcos e oficinas: percursos do teatro em Portugal do século XVIII». En Actas do Colóquio Touros, Comédias, Bailes e Tragédias [edición en línea]. Accesible en: <https://repositorio.ul.pt/bitstream/ 10451/30170/1/Jos\%c3\%a9Cam\%c3\%b5es_labirintos.pdf $>$. Fecha de acceso: 12 de marzo de 2020.

Castaño, Joana. 2017. «Los amantes sin ochavo: ¿el primer sainete portugués?». Anagnórisis. Revista de investigación teatral 15: 419-443.

Centeno, Yvette K. 1991. As três cidras do amor. Lisboa: Cotovia.

Cervantes, Miguel de. 2011. Don Quijote de la Mancha, ed. Francisco Rico. Madrid: Santillana Ediciones Generales.

Cobelo, Silvia. 2010. «A tradução tardia do Quixote em Portugal». TradTerm 16: 193-216.

Costigan, Lúcia Helena. 2009. «Vida do grande Dom Quixote e do gordo Sancho Pança, de Antonio José da Silva e Don Quixote de La Mancha, de Miguel de Cervantes». Signótica 21 (1): 89-102. 
Dotras Bravo, Alexia. 2016. «La recepción de Miguel de Cervantes en el Portugal contemporáneo». Edad de Oro XXXV: 135-147.

Entremez Intitulado O Grande Governador da Ilha dos Lagartos. 1784. Lisboa: Officina de Francisco Borges de Sousa.

Escudero Baztán, Juan Manuel. 2016. «De huellas y sucedáneos quijotescos en los entremeses del Siglo de Oro». Alpha 43: 191-203.

Figueiredo, Fidelino de. 1920. «O Thema do Quijote na Literatura Portuguesa do Século XVIII». Revista de Filología Española VII: 47-56.

Figueiredo, Fidelino de. 1921. «O Thema do Quijote na Literatura Portuguesa do Século XIX». Revista de Filología Española VIII: 161-169.

Friedman, Edward H. 1997. «The Fortunes of Chivalry: António José da Silva's Vida do Grande D. Quixote de La Mancha e do Gordo Sancho Pança». Cervantes: Bulletin of the Cervantes Society of America XVII, 2: 80-93.

Garrett, Almeida. 2015. Fragmentos Romanescos, ed. Ofélia Paiva Monteiro y Maria Helena Santana. Lisboa: Imprensa Nacional - Casa da Moeda.

Glaser, Edward. 1955. «The literary fame of Cervantes in seventeenth-century Portugal». Hispanic Review XXIII, 3: 200-211.

Glaser, Edward. 1956. «More about the literary fame of Cervantes in seventeenth-century Portugal». Anales Cervantinos V: 143-157.

Guerrini, Maria Teresa. 2001. «New documents on Samuel Usque, the author of the Consolaçam as tribulaçoens de Israel». Sefarad: Revista de Estudios Hebraicos y Sefardies 61 (1): 83-90.

Herrero, Miguel, ed. 1948. Entremés de don Quijote. Madrid: CSIC.

Jurado Santos, Agapita. 2005. Obras teatrales derivadas de novelas cervantinas (siglo XVII). Para una bibliografía. Kassel: Reichenberger.

Kawan, Christine Shojaei. 2004. «Reflections on International Narrative Research on the Example of the Tale of the Three Oranges». Folclore 27: 29-48.

López-Ríos Moreno, Santiago. 1997. «La parodia del caballero salvaje en el episodio de Camilote de la Tragicomedia de Don Duardos». En Comentarios de textos hispánicos. Homenaje al profesor Miguel Ángel Garrido Gallardo, eds. José Luis García Barrientos y Esteban Torres Serrano, 259-272. Madrid: Síntesis.

Luzán, Ignacio de. 1751. Memorias literarias de Paris: actual estado y méthodo de sus estudios. Madrid: Imprenta de don Gabriel Ramírez.

Machado, Diogo Barbosa. 1747. Bibliotheca Lusitana Historica, Critica, e Chronologica. Na qual se comprehende a noticia dos authores Portuguezes, e das Obras, que compuserão desde o tempo da promulgação de Ley da Graça até o tempo prezente. Lisboa Occidental: Officina de Antonio Isidoro da Fonseca - Officina de Ignacio Rodrigues - Officina Patriarcal de Francisco Luiz Ameno, 1741-1759, 4 vols.

Madroñal, Abraham. 2008. «El olvidado Entremés de don Quijote de Nuño Nisceno Sutil». Anales Cervantinos XL: 311-332. https://doi.org/10.3989/anacervantinos.2008.015.

Miranda, José da Costa. 1990. Estudos luso-italianos. Poesia épico-cavaleiresca e teatro setecentista. Lisboa: Instituto de Cultura e Língua Portuguesa.

Molinari, Cesare. 1985. La commedia dell'arte. Milán: Mondadori.

Nicoll, Allerdyce. 1963. The World of Harlequin: A Critical Study of the Commedia dell'Arte. Cambridge: Cambridge University Press.

Nisceno Sutil, Nuno. 1709. Musa jocoza de varios entremezes portuguezes \& castelhanos. Lisboa: Officina de Miguel Manescal.

Nogueira, Carlos. 2012. «A Literatura de cordel portuguesa». eHumanista 21: 195-222.

Palma-Ferreira, João. 1981. Do pícaro na literatura portuguesa. Lisboa: Instituto de Cultura e Língua Portuguesa. 
Pedroso, Zófimo Consiglieri. 1910. Contos Populares Portugueses. Lisboa: Livraria Ferreira.

Piquena Pessa intitulada As tres Cidras do Amor, ou O Cavalleiro Andante. 1793. Lisboa: Officina de Francisco Borges de Sousa.

Rodrigues, Maria Idalina Resines. 2006. «Vícios e virtudes da imaginação: El Quijote no teatro Português». Península. Revista de Estudos Ibéricos 3: 173-186.

Sampaio, Albino Forjaz de. 1920. Subsídios para a história do teatro português. Teatro de cordel. Lisboa: Imprensa Nacional de Lisboa.

Santos, Ana Clara. 2013. «Réception de la comédie française au Portugal (XVIII ${ }^{\mathrm{e}}$-XIX ${ }^{\mathrm{e}}$ siècles)». Anales de Filología Francesa 23: 365-383.

Silva, António José da. 1744. Theatro comico Portuguez, ou collecção das operas Portuguezas, que se representarão na Casa do Theatro publico do Bairro Alto. Lisboa: Regia Officina Sylviana e da Academia Real.

Stiffoni, Gian Giacomo. 1998. «La ópera cómica italiana en la corte portuguesa durante el reinado de João V (1728-1740)». Revista Portuguesa de Musicologia 7-8: 163-198.

Vargas Díaz-Toledo, Aurelio. 2012a. «Análisis de un texto portugués sobre el Quijote: la Relaçam de tudo o que sucedeu no sítio e defensa da grande cidade de Praga». Anales Cervantinos XLIV: 289-318. https://doi.org/10.3989/anacervantinos.2012.015.

Vargas Díaz-Toledo, Aurelio. 2012b. Os livros de cavalarias portugueses dos séculos XVIXVIII. Lisboa: Pearlbooks.

Vargas Díaz-Toledo, Aurelio. 2015. «Novedades en torno al estudio de Cervantes en Portugal: siglos XVII y XVIII». Revista Cálamo Faspe. Lengua y literatura españolas 64: 82-91.

Vargas Díaz-Toledo, Aurelio. 2018. «Rescate de una edición olvidada del Quijote (Lisboa, à custa de los hermanos Du Beux, Lagier \& Socios, 1775)». Hipogrifo. Revista de literatura y cultura del Siglo de Oro 6 (2): 311-335.

Vargas Díaz-Toledo, Aurelio y José Manuel Lucía Megías, eds. 2018. Cervantes e Portugal: História, Arte e Literatura. Oporto: Estratégias Criativas - Fundação Calouste Gulbenkian.

Vieira, Maria Augusta da Costa. 2019. «El teatro en escena: Vida do grande D. Quixote de la Mancha e do gordo Sancho Pança de Antonio José Da Silva (el Judío)». En Recepción e interpretación del Quijote, eds. Emilio Martínez Mata y Pablo José Carvajal Pedraza, 95-107. Madrid: Visor.

Recibido: 30 de octubre de 2019

Aceptado: 1 de febrero de 2020 
